\title{
Comparison of implant failure rates of different plates for midshaft clavicular fractures based on fracture classifications
}

\author{
Yung-Cheng Chiu ${ }^{1,2}$, Kui-Chou Huang ${ }^{3,4}$, Cheng-Min Shih ${ }^{5,6}$, Kun-Tsan Lee $^{5,7}$, Kun-Hui Chen ${ }^{5,8}$ and \\ Cheng-En $\mathrm{Hsu}^{5,9^{*}}$
}

\begin{abstract}
Backgrounds: The aim of our study was to investigate failure rates of reconstruction plate and non-reconstruction plate, and find the best strategy for implant selection for different fracture types for midshaft clavicular fractures.

Patients and methods: Two hundred twenty-six consecutive patients with midshaft clavicular fractures who received open reduction and plate fixation during Jan 2012 to July 2017 were reviewed. The correlations between implant failure rates and risk factors including demographic data, fracture classifications, and implant types were analyzed.

Results: AO/OTA fracture classification and plate types are the most important factors affecting implant failure for midshaft clavicular fractures. Reconstruction plate had a significantly higher failure rate (53\%) than that of non-reconstruction plates (3\%) in comminuted midshaft clavicular (AO/OTA 15-2C) fractures ( $P$ value $<0.01$ ). However, the difference was not significant in AO/OTA 15-2A and 2B classifications.

Conclusion: Patients with comminuted midshaft clavicular (AO/OTA 15-2C) fractures treated with reconstruction plates had very high implant failure rates compared to non-reconstruction plates. We suggested that patients with comminuted midshaft clavicular (AO/OTA 15-2C) fractures treated with reconstruction plates need more protection and more frequent follow-up in the postoperative period.
\end{abstract}

Keywords: Dynamic compression plate, Locking plate, Midshaft clavicular fracture, Open reduction and internal fixation, Reconstruction plate

\section{Introduction}

Midshaft clavicular fractures were traditionally treated non-operatively, although they were associated with a lower nonunion rate compared with operative treatment [1]. However, recent multicenter, randomized control studies reported that open reduction and internal fixation (ORIF) had much lower nonunion and malunion rates as well as better shoulder function compared with non-operative treatment [2-4]. Thus, ORIF with plates is considered to be the gold standard treatment for midshaft clavicular fracture. Though ORIF effectively improves

\footnotetext{
* Correspondence: jacobhe2001@gmail.com

${ }^{5}$ Department of Orthopedics, Taichung Veterans General Hospital, Taichung, Taiwan

${ }^{9}$ Sports Recreation and Health Management Continuing Studies-Bachelor's Degree Completion Program, Tunghai University, Taichung, Taiwan

Full list of author information is available at the end of the article
}

treatment outcomes, complications such as infection, hardware irritation, and implant failure diminish both patient satisfaction and functional outcome of the operation [4]. Implant failure is a major complication which often results in nonunion, malunion, and reoperation for midshaft clavicular fractures $[5,6]$.

Implant failure for midshaft clavicular fractures may be due to bending, breakage of plates, or screw dislodgement. Its incidence varies widely from 0 to $12.6 \%$ among the different fracture classifications and plates in the literature $[5,7-10]$. However, there are few precise data on the implant failure rates of each plate based on different fracture classifications.

Four major types of plates are used for midshaft clavicular fracture fixation, as follows: reconstruction plates, locking reconstruction plates, dynamic compression 
plates (DCPs), and pre-contoured locking compression plates (LCPs).

Reconstruction plates, which are available in a locking and non-locking design, have a low profile and notched edges that allow easy contouring to fit the anatomical shape of the clavicle. However, the decreased plate stiffness may also reduce its resistance to fracture deformity force, which may result in yield implant failure.

DCPs are straight and stronger than reconstruction plates, but it is difficult to fit them to the anatomic S-shape of the clavicle, which may lead to implant prominence and irritation. There is potential risk of screw loosening when bone and plate are unmatched [11]. Recently, anatomically pre-contoured LCPs were introduced. They allow the application of a plate onto the clavicle without bending. LCPs induce less irritation and are more resistant to deformity force which may decrease the failure rate.

The purpose of our study was to investigate failure rates of reconstruction plate and non-reconstruction plates and find the best strategy for implant selection for different fracture types for midshaft clavicular fractures.

\section{Materials and methods \\ Patient enrollment}

The study was performed according to international standard. All authors of the present study conducted this research ethically according to international standard as required by the journal [12]. The design of this study has also been proved by our local Ethics committee (number IRBTCVGHCE17162B).
The medical records of patients with a clavicle fracture who were treated with open reduction and internal fixation in our department between January 2012 and July 2017 were reviewed retrospectively. Patients were identified using the procedure code for open reduction and internal fixation of clavicular fractures. The indications for ORIF were mid-third clavicle fracture with more than one shaft width of displacement, more than $2 \mathrm{~cm}$ shortening, and impending open fractures. The exclusion criteria were pathologic fracture, previous fracture at the same region, fracture nonunion, open fractures, and the follow-up time was shorter than 12 weeks. All clavicular shaft fractures were classified according to the AO/OTA classification system. The chart of patient enrollment is shown in Fig. 1.

\section{Surgery}

Surgery was undertaken using a surgeon-specific longitudinal or oblique incision over the injured clavicle. When possible, inter-fragmentary lag screw was used for temporary fixation followed by rigid fixation with a reconstruction plate, locking reconstruction plate (Synthes, Bochum, Germany), dynamic compression plate (DCP), or pre-contoured locking compression plate (LCP superior clavicle plate, Synthes, Bochum, Germany). The plates were selected according to the surgeon preference. The plates were contoured by the surgeon to fit the shape of the clavicle and were all positioned on the superior surface of the bone with a minimum of three bicortical screws in both the proximal and distal end.

Jan. 2012-Oct. 2017 All acute clavicular fracture $n=319$

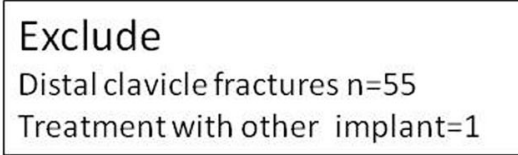

Mid-shaft clavicular fracture treated with ORIF with plates $n=263$

$$
\begin{aligned}
& \text { Follow-up } \\
& \text { Nonunion } n=4 \\
& \text { Follow-up less than } 3 \text { months } n=33
\end{aligned}
$$

Patients included for analysis $n=226$

Fig. 1 The flowchart of patient enrollment 


\section{Postoperative treatment and follow-up}

Postoperative treatment was active non-weight-bearing motion exercises of the shoulder within the first 8 weeks. Patients were allowed to start weight-bearing motion exercises after satisfactory radiographic findings after 8 weeks follow-up.

All the operated clavicles were evaluated radiographically in the anteroposterior (AP) view and $30^{\circ}$ caudal and cephalic tilt $(\mathrm{CC})$ view immediately and every month after operation until union was achieved. Bone union is defined as cortical bridging of at least three of cortices radiographically and no tenderness at the fracture site clinically [13].

\section{Treatment outcome assessments}

Implant failure was defined as the occurrence of any of the following events: (1) dislodge or loosening of the screws, (2) breakage of the plate, and (3) any angle change of the plate compared to postoperative radiographies during the 3-month postoperative follow-up [8] (Fig. 2). Nonunion was defined as no progression of radiographic healing in the first 12 months of treatment. Reoperation was defined as the requirement of a second operation for implant failure or nonunion. Patients who requested elective removal of an implant were not included in the analysis.

\section{Statistical analysis}

Data analysis was performed using SPSS software (Version 19.0; Chicago, Illinois). Univariate analysis was performed using frequencies for descriptive statistics. Chi-square and Fisher's exact test were used in the analysis of categorical variables. Logistic regression was performed to evaluate the risk predictors of implant failure. The covariates with a $P$ value $\leq 0.1$ in the univariate analysis were included in the multivariate analysis. Correlations were considered significant if $P$ values were less than 0.05 (two-sided).

\section{Results}

Three hundred nineteen consecutive patients received operation for acute clavicle fracture during the period Jan 2012 to July 2017 in our hospital, of whom 263 patients had a midshaft clavicular fracture that was treated with open reduction and plating. Thirty-seven patients were excluded during follow-up because of fracture nonunion $(n=4)$ and a follow-up time shorter than 12 weeks $(n=33)$. The remaining 226 patients with 226 midshaft clavicular fractures were included in the final analysis (Fig. 1). There were 148 males (66\%) and 78 females (35\%) with a mean age at operation of 43.5 years (13 to 87). Their mean follow-up time was 60.3 weeks (27 to 274). One hundred fifty-nine patients were treated with reconstruction plates and 67 patients were treated with non-reconstruction plates. Among the 67 patients, 19
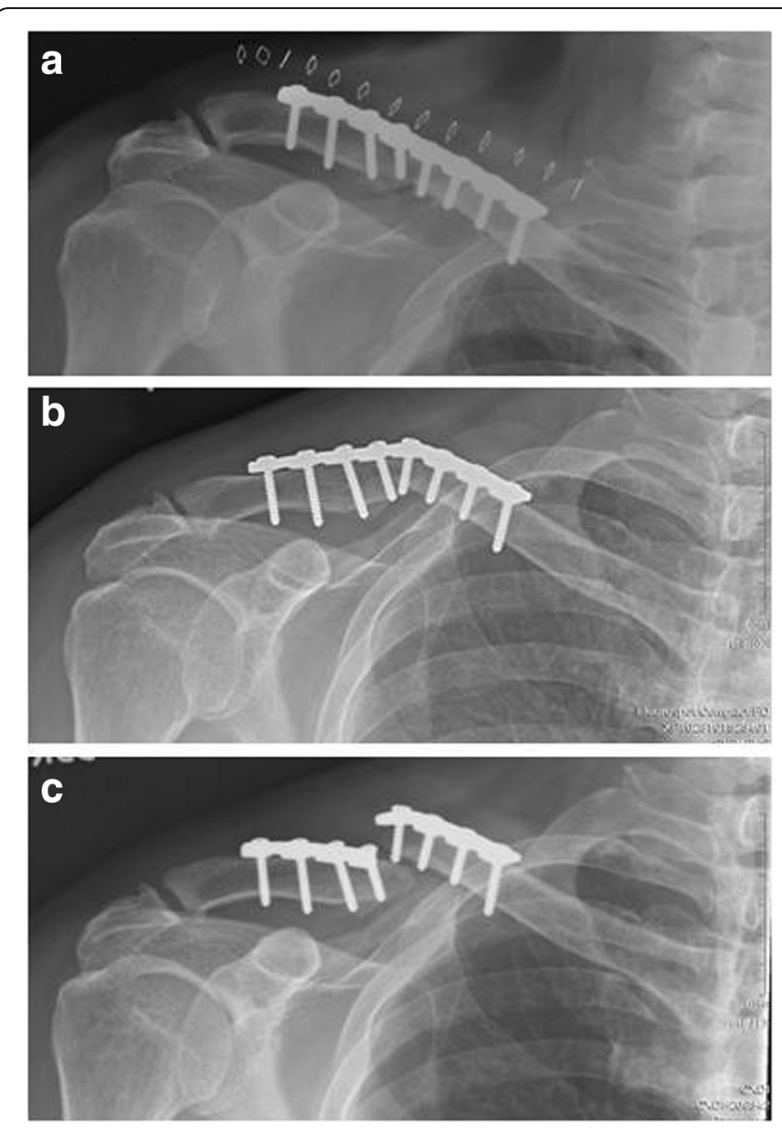

Fig. 2 a 56- year-old male patient with midshaft clavilcular fracture after open reduction and fixation with reconstruction plate. $\mathbf{b}$ Obvious bending of plate was observed at the 6-week follow-up radiograph. c Complete break of plate was found at the 8-week follow-up radiograph. The patient received reoperation and fixation with locking plate. Uneventful bone union was found 12 weeks later

were treated with locking reconstruction plates, 20 with DCPs, and 28 with pre-contoured LCPs.

Thirty-one implant failure cases were found among the 226 patients in the 3-month postoperative period, and thus the implant failure rate was $13.7 \%$. The implant failure rates of reconstruction plates and non-reconstruction plates were $16.9 \%$ and $6.0 \%$ respectively. A detailed list of implant failure causes are provided in Table 1. Eight (2.6\%) of the patients received revision surgeries with non-reconstruction plate fixation. All of them achieved

Table 1 Details of implant failure

\begin{tabular}{ll}
\hline Type of treatment failure & $\begin{array}{l}\text { Total subjects } \\
N=226(\%)\end{array}$ \\
\hline Implant failure & $31(13.7)$ \\
Plate breakage & $4(1.8)$ \\
Bending of plate & $18(8.0)$ \\
Screw loosening & $9(3.9)$ \\
\hline
\end{tabular}


uneventful bone union after at least 22 weeks follow-up. For the other 23 patients with implant failure who did not receive revision surgery, one patient did not achieve bone union until the last follow-up OPD at 6 months after operation. Twenty-two patients experienced delayed union and various degrees of mal-union. The average union time was 35 weeks. All of 195 patients without implant failure achieved uneventful bone union with average union time of 12 weeks. The predictors of implant failure risk based on demographic data and implant failure rate are summarized in Table 2 . Significantly higher failure rates were found in the $15-2 \mathrm{C}$ fracture type, reconstruction plate, and male gender groups.

In the regression analysis of significant risk factors, gender, AO/OTA fracture classification, and implant type met the criteria and were included in the multivariate analysis. AO/OTA 15-2C fracture classification and the use of reconstruction plates were found to have a statistically significant effect on implant failure rates after multivariate adjustment (Table 3).

Stratified analysis was performed to determine the relationship between implant failure rates for reconstruction plate and pre-contoured LCP in different AO/OTA classifications. Reconstruction plates had a significantly higher failure rate than LCPs for comminuted midshaft clavicular fracture $($ AO/OTA $15-2 C)(P<0.001)$. However, the difference was not significant for AO/OTA 152A and 2B fracture classifications (Table 4).

Table 2 Basic characteristic of 226 mid-shaft clavicular fractures treated with open reduction and plate fixation

\begin{tabular}{|c|c|c|c|c|}
\hline Variables & $\begin{array}{l}\text { Total (\%) } \\
N=226\end{array}$ & $\begin{array}{l}\text { Union (\%) } \\
N=195\end{array}$ & $\begin{array}{l}\text { Implant failure (\%) } \\
N=31\end{array}$ & $P$ value \\
\hline Age, years & & & & 0.318 \\
\hline$<60$ & $184(81)$ & $161(83)$ & 23(74) & \\
\hline$\geq 60$ & $42(19)$ & $34(17)$ & $8(26)$ & \\
\hline Gender & & & & 0.024 \\
\hline Male & $148(66)$ & $122(63)$ & $26(84)$ & \\
\hline Female & $78(35)$ & $73(37)$ & $5(16)$ & \\
\hline Injured side & & & & 0.327 \\
\hline Right & $90(40)$ & 75 (39) & $15(48)$ & \\
\hline Left & $136(60)$ & $120(62)$ & $16(52)$ & \\
\hline AO Classification & & & & $<0.001$ \\
\hline $15-2 \mathrm{~A}$ & $106(47)$ & $101(52)$ & $5(16)$ & \\
\hline $15-2 B$ & $61(27)$ & $52(27)$ & $9(29)$ & \\
\hline $15-2 C$ & $59(26)$ & $42(22)$ & $17(55)$ & \\
\hline \multicolumn{5}{|l|}{ Implant } \\
\hline Non-recon & $67(30)$ & $63(32)$ & $4(13)$ & 0.033 \\
\hline Recon & $159(70)$ & $132(68)$ & $27(87)$ & \\
\hline
\end{tabular}

\section{Discussion}

The aim of this investigation was to determine the main risk factors of implant failure for midshaft clavicular fractures and to compare the implant failure rates between the reconstruction plate and non-reconstruction plate based on different fracture classifications. Our finding showed that (1) significant risk factors for implant failure or midshaft clavicular fractures were AO/OTA classification and plate type, and (2) reconstruction plates had a significantly higher failure rate than nonreconstruction plates in comminuted (AO/OTA 152C) fractures.

Reconstruction plates are widely used for mid-clavicular fracture fixation, but their implant failure rates vary considerably in the literature. A review of previous studies is summarized in Table 5. Studies with smaller case numbers reported lower implant failure rates than in our study $[8,9,14-16]$. However, two studies with over 100 cases reported implant failure rates of $12 \%$ and $12.6 \%$, which were similar to our results $[5,7]$.

Locking reconstruction plates is thought to achieve a better outcome owing to their increased angular stability for screws and plate. In the literature, locking reconstruction plates were reported to have implant failure rates of $7 \%$ and $8.5 \%$ in studies by Cho and Liu, respectively $[17,18]$. Cho and his colleagues compared the complication rates between reconstruction plate and locking reconstruction plate for the treatment of midshaft clavicular fracture and found no significant difference in implant failure rates between the two types of implants [17]. Liu and his colleagues compared the operative outcomes between intramedullary nails and locking reconstruction plates in 51 and 59 midshaft clavicular fractures and found no significant differences in radiographic and functional outcomes. DCPs were suggested to have a lower implant failure rate compared with reconstruction plates owing to their superior strength. However, a wide range of implant failure rates for DCP have been reported in the literature [19]. Ashman et al. compared operative outcomes of 143 midshaft clavicular fractures treated with 51 DCPs and 92 reconstruction plates and reported that the implant failure rate of DCP was $1.4 \%$, which was significantly lower than that of reconstruction plates [19]. Lai et al. compared operative outcomes of 18 DCPs and 22 LCPs and found no differences in operative time, blood loss, complication rate, hospital stay, and union rate between these two implants. DCP was reported to have an implant failure rate of $16.7 \%$, which was much higher than that found in a study by Ashman [20].

Pre-contoured LCPs were reported to have good outcomes, with implant failure rates as low as $1.1 \%$ and $0.6 \%$ in two multicenter randomized controlled studies $[2,3]$. The two aforementioned studies compared the outcomes 
Table 3 Multivariant regression of predictors for implant failure

\begin{tabular}{|c|c|c|c|c|}
\hline Risk factors & Crude OR (95\% C.I.) & $P$ value & Adjusted OR (95\% C.I.) & $P$ value \\
\hline \multicolumn{5}{|l|}{ Age (years) } \\
\hline$<60$ & 1.00 (Ref.) & & & \\
\hline$\geq 60$ & 1.467 (0.679-3.993) & 0.269 & & \\
\hline \multicolumn{5}{|l|}{ Gender } \\
\hline Female & 1.00 (Ref.) & & 1.00 (Ref.) & \\
\hline Male & $3.111(1.145-8.459)$ & 0.026 & $2.249(0.770-6.569)$ & 0.138 \\
\hline \multicolumn{5}{|l|}{ Injured side } \\
\hline Right & 1.00 (Ref.) & & & \\
\hline Left & $0.667(0.311-1.427)$ & 0.296 & & \\
\hline \multicolumn{5}{|c|}{ AO/OTA classification } \\
\hline $15-2 \mathrm{~A}$ & 1.00 (Ref.) & & 1.00 (Ref.) & \\
\hline $15-2 B$ & $3.496(1.115-10.967)$ & 0.032 & $2.677(0.833-8.605)$ & 0.088 \\
\hline $15-2 C$ & $8.176(2.832-23.601)$ & $<0.001$ & $11.401(3.765-35.366)$ & $<0.001$ \\
\hline \multicolumn{5}{|l|}{ Plate type } \\
\hline Non-recon & 1.00 (Ref.) & & 1.00 (Ref.) & \\
\hline Recon & $3.222(1.081-9.602)$ & 0.036 & 6.006 (1.788-20.173) & 0.004 \\
\hline
\end{tabular}

between non-operative treatment and fixation of precontoured LCP and found that patients treated with precontoured LCP had significantly better functional and radiographic outcomes than patients who received nonoperative treatment. Our study demonstrated that all these non-reconstruction plates had a significantly lower implant failure rate than that of reconstruction plates, especially in comminuted (AO/OTA 15-2C) fractures.

Biomechanical studies also showed that DCPs and pre-contoured LCPs had higher compression stiffness, torsion stiffness, and cantilever bending failure load than reconstruction plates [21, 22], while locking reconstruction plates only had higher compression stiffness than

Table 4 The relationship between implant failure rates for reconstruction plate and pre-contoured LCP in different AO/ OTA classifications

\begin{tabular}{llll}
\hline & $\begin{array}{l}\text { Union } \\
N=159\end{array}$ & $\begin{array}{l}\text { Implant failure } \\
N=31\end{array}$ & $P$ value \\
\hline AO/OTA 15-2A & & & 0.613 \\
Non-recon (\%) & $27(93)$ & $2(7)$ & \\
Recon (\%) & $74(96)$ & $3(4)$ & 1.000 \\
AO/OTA 15-2B & & & \\
Non-recon (\%) & $8(89)$ & $1(11)$ & \\
Recon (\%) & $44(85)$ & $8(15)$ & $<0.001$ \\
AO/OTA 15-2C & & & \\
Non-recon (\%) & $28(97)$ & $1(3)$ & \\
Recon (\%) & $14(47)$ & $16(53)$ & \\
\hline
\end{tabular}

reconstruction plates [23]. This may explain why nonreconstruction plate had lower implant failure rate in the present study.

In $\mathrm{AO} / \mathrm{OTA} 15-2 \mathrm{~A}$ and $15-2 \mathrm{~B}$ fractures, there was no significant difference in implant failure rates between reconstruction plates and non-reconstruction plate. This finding suggests that the strength of reconstruction plates may be sufficient for non-comminuted fractures, which can be relatively easily fixed by anatomic reduction. In comminuted (AO/OTA15-2C) fractures, the strength of the plate is the most important factor for fracture stability, especially when anatomic reduction is hard to achieve.

There were several limitations in this study. First, the operations were not performed by a single surgeon. The operative skills of surgeons may have been varied and this could have affected the treatment outcome. Second, the bending and breaking of plates were only evaluated by radiography, so some implant failures could have been missed. However, four implants failed in our study, which was a higher rate than those reported in the literature. The higher implant failure rate in our study may be due to our inclusion of plate bending as a cause of implant failure, whereas most previous studies did not include this type $[7,8,15,16]$. Third, due to the retrospective nature of this study, factors that may confound the effects of treatment method on outcomes, such as bone density and bone quality, BMI, mechanism of injury, smoking, dominant arm, mental status, shoulder function, and plate irritation, were not included in our statistical analysis. Fourth, the numbers of cases in the locking reconstruction plate and DCP groups were too 
Table 5 Implant failure rates for reconstruction plates in the literature

\begin{tabular}{|c|c|c|c|c|}
\hline Author, year & Patient number & Plate location & AO/OTA classification & Implant failure rate \\
\hline Galdi et al. 2013 [12] & 18 & Anterior & $\mathrm{B} 1, \mathrm{~B} 2$, and $\mathrm{B} 3$ & $0 \%$ \\
\hline Mirzatolooei et al. 2011 [9] & 26 & Superior & Not mentioned & $7 \%$ \\
\hline Tarng et al. 2012 [14] & 32 & Superior & $\mathrm{B} 1, \mathrm{~B} 2$, and $\mathrm{B} 3$ & Not mentioned \\
\hline Kulshrestha et al. 2011 [13] & 45 & Superior & $\mathrm{B} 1, \mathrm{~B} 2$, and $\mathrm{B} 3$ & Not mentioned \\
\hline Gilde et al. 2014 [8] & 71 & Anterior & $\mathrm{B} 1, \mathrm{~B} 2$, and $\mathrm{B} 3$ & $8.5 \%$ \\
\hline Chen et al. 2012 [10] & 84 & Not mentioned & $\mathrm{B} 1$ and $\mathrm{B} 2$ & $7 \%$ \\
\hline Woltz et al. 2016 [6] & 111 & Superior and anterior & $\mathrm{B} 1, \mathrm{~B} 2$, and $\mathrm{B} 3$ & $12.6 \%$ \\
\hline Shin et al. 2012 [7] & 125 & Superior & $\mathrm{B} 2$ and $\mathrm{B} 3$ & $12 \%$ \\
\hline
\end{tabular}

small to achieve statistical significance. Further studies with a larger population should be done to confirm these results.

\section{Conclusion}

We found that patients with comminuted midshaft clavicular (AO/OTA 15-2C) fractures treated with reconstruction plates had very high implant failure rates compared to nonreconstruction plates. These findings may provide useful information that orthopedic doctors can use to identify patients who have a higher risk for implant failure. We also suggested that patients with comminuted midshaft clavicular (AO/OTA 15-2C) fractures treated with reconstruction plates need more protection and more frequent follow-up in the postoperative period.

\section{Abbreviations}

AO/OTA: Arbeitsgemeinschaft für Osteosynthesefragen/Orthopedic Trauma Association; AP: Anteroposterior; CC: Caudal and cephalic tilt; DCP: Dynamic compression plate; LCP: Locking compression plate; ORIF: Open reduction and internal fixation

\section{Acknowledgements}

KTL, KHC, and YCC made equal contributions to this work. We appreciate the assistance of the editors and anonymous referees who reviewed this study.

\section{Authors' contributions}

YCC, KCH, and CEH participated in the design of the study. YCC, KHC, and KTL carried out the measurement. CMS, CEH, and KHC carried out the statistical analysis. $\mathrm{CEH}, \mathrm{KCH}$, and TCC conceived of the study, and participated in its design and coordination and draft the manuscript. All authors read and approved the final manuscript.

\section{Funding}

Not applicable.

\section{Availability of data and materials}

The datasets used and analyzed during the current study are available from the corresponding author on reasonable request.

\section{Ethics approval and consent to participate}

Institutional approval from a local research ethics committee (number IRBTCVGHCE17162B).

\section{Consent for publication}

Not applicable.

\section{Competing interests}

No authors of this study have any financial and personal relationships with other people or organizations, which could result in an inappropriate influence of this study.

\section{Author details}

${ }^{1}$ Department of Orthopedics, China Medical University Hospital, Taichung, Taiwan. ${ }^{2}$ School of Medicine, China Medical University, Taichung, Taiwan. ${ }^{3}$ Department of Orthopedics, Asia University Hospital, Taichung, Taiwan. ${ }^{4}$ Department of Occupational Therapy, Asia University, Taichung, Taiwan. ${ }^{5}$ Department of Orthopedics, Taichung Veterans General Hospital, Taichung, Taiwan. ${ }^{6}$ Institute of Biomedical Engineering, National Chiao Tung University, Hsinchu, Taiwan. ${ }^{7}$ Department of Veterinary Medicine, College of Veterinary Medicine, National Chung Hsing University, Taichung, Taiwan. ${ }^{8}$ Department of Biomedical Engineering, Hung Kuang University, Taichung, Taiwan. ${ }^{9}$ Sports Recreation and Health Management Continuing Studies-Bachelor's Degree Completion Program, Tunghai University, Taichung, Taiwan.

Received: 2 November 2018 Accepted: 4 July 2019

Published online: 16 July 2019

\section{References}

1. Rowe CR. An atlas of anatomy and treatment of midclavicular fractures. Clin Orthop Relat Res. 1968;58:29-42.

2. Robinson CM, Goudie EB, Murray IR, Jenkins PJ, Ahktar MA, Read EO, Foster CJ, Clark K, Brooksbank AJ, Arthur A, et al. Open reduction and plate fixation versus nonoperative treatment for displaced midshaft clavicular fractures: a multicenter, randomized, controlled trial. J Bone Joint Surg Am. 2013;95(17): 1576-84.

3. Ahrens PM, Garlick NI, Barber J, Tims EM. Clavicle trial collaborative G: the clavicle trial: a multicenter randomized controlled trial comparing operative with nonoperative treatment of displaced midshaft clavicle fractures. J Bone Joint Surg Am. 2017;99(16):1345-54.

4. Canadian Orthopaedic Trauma S. Nonoperative treatment compared with plate fixation of displaced midshaft clavicular fractures. A multicenter randomized clinical trial. J Bone Joint Surg Am. 2007;89(1):1-10.

5. Woltz S, Duijff JW, Hoogendoorn JM, Rhemrev SJ, Breederveld RS, Schipper IB, Beeres FJ. Reconstruction plates for midshaft clavicular fractures: a retrospective cohort study. Orthop Traumatol Surg Res. 2016;102(1):25-9.

6. Biz C, Tagliapietra J, Angelini A, Belluzzi E, Pozzuoli A, Berizzi A, Ruggieri P. The challenging management of a delayed union midshaft clavicle fracture complicated by an acute pseudoaneurysm of the subclavian artery in a superelderly diabetic patient. Aging Clin Exp Res. 2019;31(4):567-9.

7. Shin SJ, Do NH, Jang KY. Risk factors for postoperative complications of displaced clavicular midshaft fractures. J Trauma Acute Care Surg. 2012; 72(4):1046-50.

8. Gilde AK, Jones CB, Sietsema DL, Hoffmann MF. Does plate type influence the clinical outcomes and implant removal in midclavicular fractures fixed with 2.7-mm anteroinferior plates? A retrospective cohort study. J Orthop Surg Res. 2014;9:55

9. Mirzatolooei F. Comparison between operative and nonoperative treatment methods in the management of comminuted fractures of the clavicle. Acta Orthop Traumatol Turc. 2011:45(1):34-40. 
10. Chen YF, Wei HF, Zhang C, Zeng BF, Zhang CQ, Xue JF, Xie XT, Lu Y. Retrospective comparison of titanium elastic nail (TEN) and reconstruction plate repair of displaced midshaft clavicular fractures. J Shoulder Elb Surg. 2012;21(4):495-501.

11. Shahid R, Mushtaq A, Maqsood M. Plate fixation of clavicle fractures: a comparative study between reconstruction plate and dynamic compression plate. Acta Orthop Belg. 2007;73(2):170-4.

12. Padulo J, Oliva F, Frizziero A, Maffulli N. Muscles, ligaments and tendons journal-basic principles and recommendations in clinical and field science research: 2016 update. Muscles Ligaments Tendons J. 2016;6(1):1-5.

13. Goldhahn J, Mitlak B, Aspenberg P, Kanis JA, Rizzoli R, Reginster JY. Fracturehealing GWGoB: critical issues in translational and clinical research for the study of new technologies to enhance bone repair. J Bone Joint Surg Am. 2008;90(Suppl 1):43-7.

14. Galdi B, Yoon RS, Choung EW, Reilly MC, Sirkin M, Smith WR, Liporace FA. Anteroinferior $2.7-\mathrm{mm}$ versus $3.5-\mathrm{mm}$ plating for AO/OTA type B clavicle fractures: a comparative cohort clinical outcomes study. J Orthop Trauma. 2013;27(3):121-5.

15. Kulshrestha V, Roy T, Audige L. Operative versus nonoperative management of displaced midshaft clavicle fractures: a prospective cohort study. J Orthop Trauma. 2011;25(1):31-8.

16. Tarng YW, Yang SW, Fang YP, Hsu CJ. Surgical management of uncomplicated midshaft clavicle fractures: a comparison between titanium elastic nails and small reconstruction plates. J Shoulder Elb Surg. 2012;21(6): 732-40.

17. Cho CH, Song KS, Min BW, Bae KC, Lee KJ. Operative treatment of clavicle midshaft fractures: comparison between reconstruction plate and reconstruction locking compression plate. Clin Orthop Surg. 2010;2(3):154-9.

18. Liu HH, Chang CH, Chia WT, Chen CH, Tarng YW, Wong CY. Comparison of plates versus intramedullary nails for fixation of displaced midshaft clavicular fractures. J Trauma. 2010;69(6):E82-7.

19. Ashman BD, Slobogean GP, Stone TB, Viskontas DG, Moola FO, Perey BH, Boyer DS, McCormack RG. Reoperation following open reduction and plate fixation of displaced mid-shaft clavicle fractures. Injury. 2014;45(10):1549-53.

20. Lai YC, Tarng YW, Hsu CJ, Chang WN, Yang SW, Renn JH. Comparison of dynamic and locked compression plates for treating midshaft clavicle fractures. Orthopedics. 2012;35(5):e697-702.

21. Eden L, Doht S, Frey SP, Ziegler D, Stoyhe J, Fehske K, Blunk T, Meffert RH. Biomechanical comparison of the locking compression superior anterior clavicle plate with seven and ten hole reconstruction plates in midshaft clavicle fracture stabilisation. Int Orthop. 2012;36(12):2537-43.

22. Iannotti MR, Crosby LA, Stafford P, Grayson G, Goulet R. Effects of plate location and selection on the stability of midshaft clavicle osteotomies: a biomechanical study. J Shoulder Elb Surg. 2002;11(5):457-62.

23. Robertson C, Celestre P, Mahar A, Schwartz A. Reconstruction plates for stabilization of mid-shaft clavicle fractures: differences between nonlocked and locked plates in two different positions. J Shoulder Elb Surg. 2009;18(2): 204-9.

\section{Publisher's Note}

Springer Nature remains neutral with regard to jurisdictional claims in published maps and institutional affiliations.

Ready to submit your research? Choose BMC and benefit from:
- fast, convenient online submission
- thorough peer review by experienced researchers in your field
- rapid publication on acceptance
- support for research data, including large and complex data types
- gold Open Access which fosters wider collaboration and increased citations
- maximum visibility for your research: over 100M website views per year
At BMC, research is always in progress.
Learn more biomedcentral.com/submissions

